\title{
Fortification of Pasta Using Different Plant Sources
}

\author{
R. Saraswathi and R. Sahul Hameed \\ Department of Home Science, the Gandhigram Rural Institute (Deemed to be University), Dindigul 624 302, India
}

\begin{abstract}
Nowadays food industries are focused on two major factors for health and convenience during the development of breakfast food and variety of snack products, because consumers have sparked the development of convenient and nutritious food products. Pasta is one of the easiest and most versatile food products consumed today. Pasta usually made from durum semolina which is hard grain wheat flour that is high in protein but lack of other nutrients such as vitamins, minerals and fibre. Recently, pasta products has developed into improve the nutritional quality by the addition of other ingredients like pulses, vegetable and fruit extracts which is help to get the nutritional well being of the consumers. One of the solutions for this is the incorporation of millet flour, pulse flour and plantain flour which were addition or replacement of durum wheat semolina to formulate healthy pasta. Hence the objective of study was aimed to develop multigrain nutrient dense pasta products prepared from composite mixture such as durum semolina, millets (barnyard millet (Echinochloa utilis), kodo millet (Paspalum setaceum) and little millet (Panicum sumatrense), pulses (peas (Pisum sativum L.) and lentil (Lens culinaris)) and vegetable (plantain flours (Musa paradisiaca)) at different proportions. It contains durum semolina flour, millet and pulse blend flour (millet flour blends (flours of barnyard millet, kodo millet, little millet mixed at ratio 1:1:1) and pulse flour blends (flours of peas and lentil mixed at ratio 1:1) both millet and pulse blends were mixed at ratio 1:1) and plantain flour. All the three flours samples were mixed at 70:15:15 percent for formulae 1, 55:30:15 percent for formulae 2 and 40:45:15 percent for formulae 3. Durum semolina (100\%) was used as control. For $15 \%$ of plantain flour addition to millet pulse blend flour increase the nutritional content of flour due to which is more fiber content. Then composite mixture of formulae and control were analyzed the nutritional properties of such as moisture $(\%)$, energy (kcal), carbohydrate (g), protein ( $\mathrm{g})$, fat $(\mathrm{g})$, crude fibre $(\mathrm{g})$, ash (\%) and minerals content were evaluated by standard procedures. Further pasta developed from composite mixtures of formulae and assessed its shelf life were also evaluated. The results showed that the composite flours of moisture content $(7.8 \%$ to $8.2 \%)$, energy ( $363.3 \mathrm{kcal}$ to $365.6 \mathrm{kcal})$, carbohydrate ( $78.4 \mathrm{~g}$ to $81.3 \mathrm{~g})$, protein $(9.4 \mathrm{~g}$ to $11.7 \mathrm{~g})$, fat $(0.1 \mathrm{~g}$ to $0.3 \mathrm{~g})$, ash $(0.72 \%$ to $1.38 \%)$ and crude fiber content $(7.88 \mathrm{~g}$ to $14.06 \mathrm{~g})$. These findings revealed that composite flour formulae of protein, ash, crude fiber content and calcium, iron, copper, zinc content were higher than control. While manganese content of all composite mixture and formulae 2 of calcium content was also lower than control. Therefore, three composite mixtures of formulae could be used to produce good quality of pasta products. Among the composite mixture, formulae1 was high score (8.81) in overall acceptability. During storage period, composite mixture of all formulae nutrients content and also sensory parameters were slightly decreased. Even though, multigrain food products that provide to improve good health and other beneficial effect but also have good taste, extended shelf life and appealing colour and are also economically feasible for all grades of population.
\end{abstract}

Key words: Composite flour, millet pulse blend flour, nutritional properties, pasta sensory attribute and shelf life.

\section{Introduction}

Wide spread of malnutrition and associated health problems around the world has put up pressure on food industries to develop food products with high nutritional properties, health benefits and novelty to consumers. Dietary based approaches should be taken into consideration while addressing deep-rooted

Corresponding author: R. Saraswathi, Ph.D. student, research field: food processing. problems like malnutrition and nutritional insecurity. Pasta is one of the versatile food products liked by the consumers of all age groups, because of its convenience in preparation and serving it. Pasta products, traditionally manufactured from durum wheat semolina, known to be the best raw material suitable for pasta production. Pasta contains $74 \%-77 \%$ of carbohydrates and $11 \%-15 \%$ of proteins [1]. Although pasta plays an integral role in regular diet, but poor nutritional value (lack of vitamins, minerals and 
fibre) of these products may lead into nutritional deficiencies on daily consumption. Researchers have been studying the possibility of improving the nutritional quality of pasta products by adding other ingredients like vegetable and fruit extracts and claiming that it may help in attaining nutritional well-being of the consumers which is a sustainable force for health and development and maximization of human genetic potential [2]. This provides an opportunity for the use of non-traditional raw materials to increase the nutritional quality of pasta. Among these non-traditional raw materials as millet, legumes represent an interesting source of proteins, fibres, vitamins and minerals [3]. Though millets have high nutritious than other cereals, even millet utilization is not considerably flourished, their utilization can be increased by a way that directs to blend them with wheat flour [4]. Millet contains nearly $15 \%$ of protein, high amounts of fiber, B-complex vitamins including niacin, thiamin and riboflavin, folic acid, the essential amino acid as methionine, lecithin and some vitamin E. Furthermore, millets are rich source of minerals such as iron, magnesium, calcium, phosphorous, manganese and potassium. The seeds are also rich in phytochemicals, including phytic acid, believed to lower cholesterol and phytate, which is associated with reduced cancer. Millet is more than just an interesting alternative to the more common grains [5]. Additionally they also have nutraceutical properties and provide health benefits like tumor incidence reduction, cardiovascular disease, low blood pressure, cholesterol problem, fat absorption rate, heart disease, gastric problems and also gastro-intestinal bulk supply $[6,7]$. Some studies were carried out that persons who consumed millet diet were found to have considerably decreased blood glucose levels [8]. Research says that millet crop proteins have high amounts of amino acids in comparison to other cereals but has less lysine and threonine content whereas methionine is relatively in higher amounts $[2,9]$. Adding exogenous ingredients rich in protein is an ideal way to get higher biological value and a better amino acid pattern. Legumes are important crops because of their nutritional quality. Pulses are rich in amino acid like lysine [10]. While pulses are deficient in methionine, but cereals are rich in methionine and deficient in lysine [11]. So when pulses are combined with cereals (a source of the amino acid like methionine), it provides the balanced protein necessary for growth [12]. Therefore, addition of pulses flour to cereal based products could be a good option to overcome the world protein calorie malnutrition problem, because pulses contain approximately three times more proteins than cereals [13]. In addition to that pulses are rich in complex carbohydrates, vitamins and minerals [14]. Consequently, legumes and cereals are nutritionally complementary food [15]. Addition with plantain (Musa paradisiaca) constitutes a rich energy source with carbohydrate content of $32 \%$ and also rich in vitamins $A, B_{1}, B_{2}$, $\mathrm{B}_{3}, \mathrm{~B}_{6}, \mathrm{C}$, dietary fibre, iron, potassium, calcium, magnesium and sulfur [16]. Recent developments in pasta products include attempts to improve the nutritional properties of pasta by the addition of supplements from various natural sources. Plantain can be very cheap to buy and important food for low income families. Therefore new economical strategy is to increase the consumptions of plantain into flour. The production of plantain flour incorporate into various innovative products such as weaning and extruded food products, it is means of value added foods and it's extend the shelf life of derived foods. Hence the plantain (unripe banana) flour is used for the food industry, mainly in bakery products, dietary products and infant foods [17]. For that reason addition of $15 \%$ plantain flour to composite flour, the product can be claimed to be functional pasta products due to the fiber and resistant starch content of the final product. Therefore the objective of the study was aimed to determine the nutritional properties of control and composite mixture such as 
durum semolina, millets (barnyard millet (Echinochloa utilis), kodo millet (Paspalum setaceum) and little millet (Panicum sumatrense)), pulses (peas (Pisum sativum L.) and lentil (Lens culinaris)) and vegetable (plantain flours (Musa paradisiaca)) at different proportions. Durum semolina $(100 \%)$ was used as control. Then formulated nutrient dense pasta products prepared from composite mixtures and studied shelf life of pasta products were evaluated by standard procedures. Thus whole grain food is good but multigrain blends helps to maximize their nutritional, functional and sensory properties. This could be utilized for the development of composite blends from locally produced millet, pulses and plantain at small scale industry level as value-added products.

\section{Materials and Methods}

\subsection{Raw Materials}

Durum wheat semolina (Triticum turgidum L. var. durum), plantain (Musa paradisiaca) were purchased from local market, Mysore, Karnataka, India and millets such as kodo millet (Paspalum setaceum), barnyard millet (Echinochloa utilis) and little millet (Panicum sumatrense) and pulses such as peas (dry) (Pisum sativum L.) and lentil (Lens culinaris) were purchased from Bombay Traders, Madurai, Tamil Nadu, India. The experiments were conducted in Food Lab, Central Food Technology Research Institute (CFTRI), Mysore, Karnataka, India. Chemicals used for the experiments were of analytical grade.

\subsection{Preparation of Raw Materials}

Durum wheat semolina, millets (kodo millet, barnyard millet and little millet) and pulses (peas and lentil) were cleaned by manual winnowing and passed on to laboratory hammer mill to produce flours. The flours were sieved using $80 \mathrm{~mm}$ BS sieve (TP series, $38 \mu \mathrm{m}-125 \mathrm{~mm}$ and Test sieve) and packed in high-density polyethylene (HDPE) bags
$(40 \mu \mathrm{m})$. Then, the flours were stored in air tight containers at refrigeration temperature $\left(4{ }^{\circ} \mathrm{C}\right)$ until further use.

\subsubsection{Preparation of Millets Flour Blend}

Millet flour blend was prepared by mixing kodo millet, barnyard millet and little millet flours at equal proportions (ratio 1:1:1, respectively).

\subsubsection{Preparation of Pulses Flour Blend}

Pulse flour blend was prepared by mixing the pea and lentil flours at ratio 1:1.

\subsubsection{Preparation of Millet and Pulses Flour Blend}

Millet and pulses flour blend was prepared by admixing millet flour blend and pulse flour blend at ratio $1: 1$.

\subsubsection{Preparation of Plantain Flour}

Plantain heads were separated from bunches which were subsequently defingered (each plantain from hand into a bowl containing water). The fingers were washed, peeled, cut into three or four pieces which were blanched for $5 \mathrm{~min}$. Then they were sliced into uniform thickness. Sliced plantain pieces were dipped into $0.2 \%$ potassium meta bisulphite (KMS) solution for $10 \mathrm{~min}$ to prevent enzymatic browning reactions and retain its colour. Plantain slices were dehydrated in a cabinet air drier at $65{ }^{\circ} \mathrm{C}$ for $8 \mathrm{~h}$. The dried chips were milled using a hammer mill, sieved the powders $(300-400 \mu \mathrm{m})$ and packed in HDPE bags $(40 \mu \mathrm{m})$ until it is needed for product development.

\subsection{Preparation of Composite Mixture of Formulae}

Composite flour prepared by mixing durum wheat semolina, millet \& pulse flour blend and plantain flour at ratio $70: 15: 15$, respectively, for formulae 1 , ratio 55:30:15 followed for formulae 2 and ratio 40:45:15 for formulae 3 and durum wheat semolina were used as control (Table 1).

\subsection{Nutritional Properties of Composite Mixture of Flour}

Nutritional properties of composite mixture of flour 
Table 1 Ingredients used for preparation of composite mixture of formulae.

\begin{tabular}{llll}
\hline Samples & Durum wheat semolina (\%) & Millet \& pulses flour blend (\%) & Plantain flour (\%) \\
\hline Control & 100 & - & - \\
Formulae 1 & 70 & 15 & 15 \\
Formulae 2 & 55 & 30 & 15 \\
Formulae 3 & 40 & 45 & 15 \\
\hline
\end{tabular}

such as moisture, fat, protein, ash, carbohydrate, energy and crude fiber were determined by following the standard procedure as described by Ref. [18].

\subsubsection{Estimation of Moisture Content}

Moisture content of the flour samples was determined by hot air oven (Toplab, Tl-Oven, 2008, Toplab India) for drying method. Two grams of well mixed flour sample was taken in a clean, dried and pre weighed Petri dish. It was then placed in an oven at $130{ }^{\circ} \mathrm{C}$ for $1 \mathrm{~h}$. The samples were cooled in a desiccator (Hamco, Chemical Laboratory, 1969, Hindustan Apparatus Mfg. Company) and weighed. The percentage of moisture was calculated as follows:

Moisture content $(\%)=\frac{W_{1}-W_{2}}{\text { Sample weight }(W)} \times 100$

where $W_{1}=$ weight of sample before oven drying; $W_{2}$ = weight of sample after oven drying.

\subsubsection{Estimation of Fat Content}

The fat content of the flour samples were determined using solvent extraction method in a Soxhlet apparatus. Two grams of moisture free flour samples was accurately weighed and wrapped in a filter paper. Then it was placed in a Soxhlet reflux flask (Soxhlet Extraction Apparatus, 2007, Standard Steel) which is connected to a condenser (HL-A1245, 1963, H.L. Scientific Industries) on the upper side and $200 \mathrm{~mL}$ of petroleum ether was added to the Soxhlet reflux flask. The ether was brought to its boiling point, the vapor condensed into the reflux flask immersing the samples completely for extraction to take place. On filling up the reflux flask siphons with condense solvent, it over flows along with oil extracted back to the boiling solvent in the flask. The process of boiling, condensation and reflux was allowed to go on for 4-5 h. The oil extract in the flux was dried in the oven at $60{ }^{\circ} \mathrm{C}$ for $1 \mathrm{~h}$ then allowed to cool in a dessicator (Hamco, Chemical Laboratory, 1969, Hindustan Apparatus Mfg. Company) and weighed until constant weight was obtained. Percentage of fat in the sample was calculated as follows:

Crude fat $(\%)=\frac{W_{2}-W_{1}}{\text { Weight of sample }(W)} \times 100$

where $W_{1}=$ weight of empty flask; $W_{2}=$ weight of flask with oil.

\subsubsection{Estimation of Protein Content}

Crude protein of the sample flours was determined using the Kjeldahl method. For digestion, $1 \mathrm{~g}$ of dry sample was dropped into the $100 \mathrm{~mL}$ Kjeldahl digestion flask. Then 2-3 g of copper sulfate and sodium sulfate (digestion mixture) and $20 \mathrm{~mL}$ of concentrated sulphuric acid $\left(\mathrm{H}_{2} \mathrm{SO}_{4}\right)$ were added to the sample. The flask was heated in electrical heater for 2-3 h until a clear solution was obtained and left for another $30 \mathrm{~min}$. The flask was removed and allowed to cool. For distillation, $4 \%$ boric acid and $40 \% \mathrm{NaOH}$ were used. The distillation apparatus was set and rinsed for $10 \mathrm{~min}$ after boiling. A $10 \mathrm{~mL}$ of the digested sample was then placed in the distillation apparatus and $20 \mathrm{~mL}$ of $40 \% \mathrm{NaOH}$ were added and the distillation was continued for $10-15 \mathrm{~min}$. The sample is automatically distilled after the addition of concentrated alkali solution $(\mathrm{NaOH} 40 \%)$ to make the medium alkaline. Ten milliliters of $4 \%$ boric acid was pipetted out into conical flask; further sample was diluted with $75 \mathrm{~mL}$ of distilled water during distillation. The diluted sample was received in $10 \mathrm{~mL}$ of $4 \%$ boric acid contained in $100 \mathrm{~mL}$ conical flask attached to the receiving end. The steam exit (ammonia evolved) of the distillatory was closed and the change of colour of 
boric acid solution to green was timed. The distillation was continued until the volume in the flask was 50 $\mathrm{mL}$ then the flask was removed from the distillatory. Then three drops of methyl red and Brome cresol green in alcohol indicator was added to the flask. The trapped ammonia (distillate) was then titrated against $0.1 \mathrm{~N}$ hydrochloric acid $(\mathrm{HCl})$ until the red color was obtained. The percentage of protein was calculated:

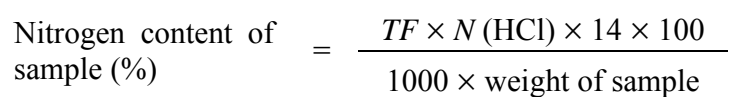

Crude protein content $(\%)=$ nitrogen content $(\%) \times$ conversion

$$
\text { factor (5.7) }
$$

where $T F=$ reading of titration; $14=$ equivalent weight of nitrogen; $N=$ normality; $5.7=$ protein factor.

\subsubsection{Estimation of Ash Content}

The ash content of composite flour sample was determined by using muffle furnace $(230 \mathrm{~V}, 50 \mathrm{~Hz}$, Single Phase 2008, M. G. Furnaces (India)). Silica crucibles were dried and cooled in desiccators before weighing. Two grams of the sample flours were weighed into the crucible and recorded the weight. The crucible containing the samples was charred over a slow burning flame and then kept into the muffle furnace and maintained the temperature of $600{ }^{\circ} \mathrm{C}$ for $3 \mathrm{~h}$ or till the appearance of a gray-white ash. The muffle furnace was then allowed to cool; the crucibles were then brought out and then transferred to a desiccator (Glass, 150-300 mm, 2010, S.K. Appliances) to cool. The percentage of ash was calculated as follows:

Ash content $(\%)=\frac{W_{2}-W_{1}}{\text { Weight of sample }} \times 100$

where $W_{1}=$ weight of empty crucible; $W_{2}=$ weight of the crucible with ash.

\subsubsection{Estimation of Carbohydrate Content}

According to Ref. [19], the carbohydrate content of the composite flour samples were calculated by using the following formula and the values were expressed in $\mathrm{g} / 100 \mathrm{~g}$.

Carbohydrate by difference $=100-[$ moisture $(\%)+$ protein $(\mathrm{g} \%)$

$$
+ \text { crude fat }(\%)+\text { ash }(\%)]
$$

\subsubsection{Estimation of Energy Value}

Calculated the energy value of the composite flour using conversion factor viz., $1 \mathrm{~g}$ of carbohydrate $=4$ $\mathrm{kcal}, 1 \mathrm{~g}$ of protein $=4 \mathrm{kcal}$ and $1 \mathrm{~g}$ of fat $=9 \mathrm{kcal}$. The sum of carbohydrate, fat and protein content of flours were summed to calculate energy value (kcal) [20].

\subsubsection{Estimation of Crude Fiber Content}

According to Ref. [21], $1 \mathrm{~g}$ of fat free and moisture free sample was added with $200 \mathrm{~mL}$ of $\mathrm{H}_{2} \mathrm{SO}_{4}$ and boiled for $30 \mathrm{~min}$ with bumping chips. Filter through muslin and wash with boiling water until washing are no longer acidic. Boil with $200 \mathrm{~mL} \mathrm{NaOH}$ solution for $30 \mathrm{~min}$. Filter through muslin cloth again and wash with $25 \mathrm{~mL}$ of boiling $1.25 \% \mathrm{H}_{2} \mathrm{SO}_{4}$, three $50 \mathrm{~mL}$ portion of water and $25 \mathrm{~mL}$ alcohol. Remove the residue and transfer to ashing dish (Pre weighed dish $\left.W_{1}\right)$. Dry the residue for $2 \mathrm{~h}$ at $130 \pm 2{ }^{\circ} \mathrm{C}$. Cool the dish in a desiccator and weigh $\left(W_{2}\right)$. Ignite for $30 \mathrm{~min}$ at $600 \pm 15{ }^{\circ} \mathrm{C}$. Cool the dish in desiccators and reweigh $\left(W_{3}\right)$. Calculate crude fiber of flour samples as follows:

Crude fiber $(\%)=\frac{\left(W_{2}-W_{1}\right)-\left(W_{3}-W_{1}\right)}{\text { Weight of sample }} \times 100$

\subsubsection{Minerals Analysis}

The estimation of mineral content of samples was described by Mahajan and Chauhan [22]. About $1 \mathrm{~g}$ sample was shaken with $10 \mathrm{~mL}$ of $0.03 \mathrm{M} \mathrm{HCl}$ for $3 \mathrm{~h}$ at $37{ }^{\circ} \mathrm{C}$ and then filtered. The clear extract obtained was oven-dried at $100{ }^{\circ} \mathrm{C}$ and then the sample was acid-digested with diacid mixture $\left(\mathrm{HNO}_{3}: \mathrm{HClO}_{4}, 5: 1\right.$, $\mathrm{v} / \mathrm{v})$ at $180{ }^{\circ} \mathrm{C}$ for $2 \mathrm{~h}$. The amount of extractable minerals such as $\mathrm{Ca}, \mathrm{Fe}, \mathrm{Cu}, \mathrm{Zn}$ and $\mathrm{Mn}$ was determined using atomic absorption spectrophotometer (A Analyst 100, Agilent, Norvalk, C.T., USA) in acetylene air flame at wavelengths: 422 , 248, 325, 214 and $279.5 \mathrm{~nm}$, respectively. Each sample was analysed thrice and the mean data are reported herein.

\subsection{Preparation of Pasta}

Pasta was prepared by composite flour such as 
durum semolina flour, millet pulses blend flour and plantain flour in different proportions at 70:15:15, 55:30:15, 40:45:15 for formulae 1, formulae 2 and formulae 3, respectively, were used to develop pasta products. Durum semolina (100\%) was used as control. Each blend (300 g) separately mixed with water added slowly within 45-60 s at slow speed in a Hobart mixer equipped with a special mixing paddle. After all water was added (to achieve the desired level of hydration at $32 \%$ moisture) the sample was mixed at low speed (speed position 1 of the mixer) for $4 \mathrm{~min}$ to reach uniform mix. The wetted dough was placed in the mixing chamber of the extruder and extruded into pasta using demaco semi commercial laboratory extruder (P3 model, Le monferrina, Masoero Arturo and C.S.N.C, Italy). Pasta was extruded using the round die (No. 62) and cut to short pieces of approximately $2 \mathrm{~cm}$ in length through blade, then pasta was dried in cabinet air drier (drying cabinet, 1988, Reliance Instruments Corporation) at $65{ }^{\circ} \mathrm{C}$ for 3-4 h. Further samples were cooled, sealed in HDPE bags $(40 \mu \mathrm{m})$ and stored at room temperature [23].

\subsection{Sensory Evaluation of Pasta Products}

Evaluation of the pasta quality characteristics was carried out room temperature for $1 \mathrm{~h}$. Sensory evaluation was performed by 10 trained panelists who were graduate students at the Department of Home Science, Fatima Arts and Science College, Madurai, Tamil Nadu, India. Pasta products were randomly assigned to each panelist. The panelists were asked to evaluate pasta for appearance, texture, color, taste, flavor and overall acceptability. A nine point hedonic scale was used where $9=$ like extremely and $1=$ dislike extremely.

\subsection{Shelf Life Studies of Pasta}

The pasta samples from composite mixture of formulae and control were subjected for assessing the storage stability. Prepared products were packed in
HDPE packs (200 gauges) and stored at ambient temperature for shelf life study. Subsequent quality analysis was as follows: pasta products were evaluated for moisture, ash and sensory analysis, at $0 \mathrm{~d}$, after 30 $\mathrm{d}$, after $60 \mathrm{~d}$, after $90 \mathrm{~d}$ and after $120 \mathrm{~d}$. The intent of the study was to determine how well the pasta products in moisture, ash content and in overall acceptability of pasta and usage though a controlled $120 \mathrm{~d}$ storage.

\subsection{Statistical Analysis}

Nutritional properties of composite flours were analysed and experiments were conducted in triplicates. Data was analyzed with the help of factorial design. Mean and standard deviations were reported. Analysis of variance (ANOVA) was performed and the results were separated using Duncan's multiple range test, which was used to know the significant differences. The relationship between the parameters was examined by Pearson's product moment correlation also done. Significance was accepted at probability $p<0.05$ using the statistical software of INSTAT (Graphpad), USA.

\section{Results and Discussion}

\subsection{Nutrient Content of Composite Flours}

Nutrient content of composite flours were presented in Table 2 and Fig. 1. It showed that moisture content of control and composite flour sample were ranged from $7.8 \%$ to $8.2 \%$. The results showed that moisture content of composite formulae were lower than control and no significant $(p>0.05)$ difference was observed between formulae 3 to control. The energy value of control and composite flour ranges from $363.3 \mathrm{kcal}$ to $365.6 \mathrm{kcal}$, composite mixture of energy value was equal to control. Further the carbohydrate content was $80.9 \%, 81.3 \%, 79.3 \%$ and $78.4 \%$ for control, composite flour formulae 1 , formulae 2 and formulae 3 , respectively. The carbohydrate content of composite flour formulae decreased than control except formulae 1. Furthermore 
Table 2 Nutrient content of composite flour formulae.

\begin{tabular}{|c|c|c|c|c|c|c|}
\hline \multirow{2}{*}{$\begin{array}{l}\text { Nutrients content } / 100 \\
\mathrm{~g} \text { of sample }\end{array}$} & \multirow{2}{*}{ Control } & \multicolumn{3}{|c|}{ Durum wheat flour substituted with composite flour } & \multirow{2}{*}{$F$ value } & \multirow{2}{*}{$p$ value } \\
\hline & & Formulae 1 & Formulae 2 & Formulae 3 & & \\
\hline Moisture (\%) & $8.2 \pm 0.05$ & $7.9 \pm 0.07^{*}$ & $7.8 \pm 0.1^{* *}$ & $8.1 \pm 0.09^{\mathrm{ns}}$ & 7.74 & 0.0095 \\
\hline Energy (kcal) & $364.5 \pm 0.2$ & $365.6 \pm 0.1^{* *}$ & $364.9 \pm 0.5^{* *}$ & $363.3 \pm 0.2^{* *}$ & 391.9 & 0.0001 \\
\hline Carbohydrate (g) & $80.9 \pm 0.07$ & $81.3 \pm 0.1^{* *}$ & $79.31 \pm 0.3^{* *}$ & $78.4 \pm 0.2^{* *}$ & 541.04 & 0.0001 \\
\hline Protein $(g)$ & $9.9 \pm 0.2$ & $9.41 \pm 0.1^{*}$ & $11.24 \pm 0.2^{* *}$ & $11.7 \pm 0.1^{* *}$ & 81.96 & 0.0001 \\
\hline Fat $(\mathrm{g})$ & $0.1 \pm 0.01$ & $0.3 \pm 0.01^{* *}$ & $0.3 \pm 0.01^{* *}$ & $0.3 \pm 0.01^{* *}$ & 146.83 & 0.0001 \\
\hline Ash (g) & $0.72 \pm 0.02$ & $1 \pm 0.01^{* *}$ & $1.29 \pm 0.01^{* *}$ & $1.38 \pm 0.02^{* *}$ & $1,485.1$ & 0.0001 \\
\hline$R^{2}$ value & & 0.9999 & 1.0000 & 0.9999 & & \\
\hline
\end{tabular}

Mean \pm standard deviation was reported; control denotes $0 \%$ composite flour substitution; $* * 1 \%$ level of significance; $* 5 \%$ level of significance; ns: not significant.

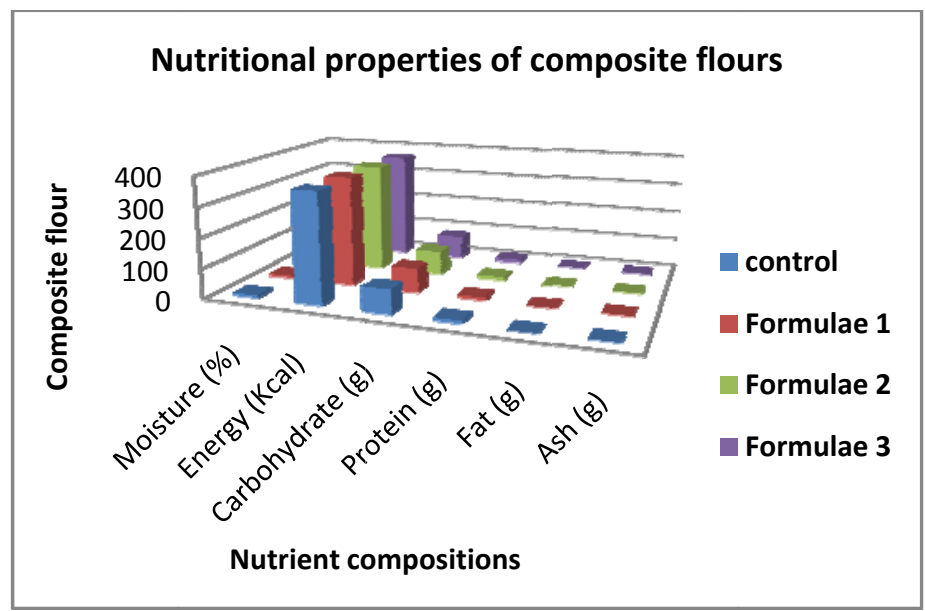

Fig. 1 Nutrient composition of composite formulae.

among the flour samples, formulae 1 had higher carbohydrate content $(81.3 \mathrm{~g})$ than other flour sample which may due to increase in the concentration of durum semolina in the composite flour formulae. A significant difference between control and composite formulae of carbohydrate content was observed $(p<$ 0.05). Among the composite mixture, formulae 3 had the highest protein content which was $11.7 \%$, followed by formulae $2(11.2 \%)$, formulae $1(9.4 \%)$ and control (9.9\%). The findings suggest that composite mixtures formulae was higher in protein content than control due to increased level of substitution of composite mixture to wheat flour and the differences were significant $(p<0.05)$ to control. Fat content of composite mixtures of all formulae had $0.3 \%$ which was noted as higher $(0.3 \%)$ than control $(0.1 \%)$ and it was significant $(p<0.05)$. Ash content of formulae was $1.38 \%, 1.29 \%$ and $1 \%$ for formulae 3 , formulae 2 and formulae 1 which was higher than control $(0.72 \%)$. The results indicate that increasing the concentration of composite mixture of flour leads to increase the ash content and the differences were significant $(p<0.05)$ to control. According to Ref. [24], Hayma reported that the moisture content of all flour samples ranges from $10.3 \%$ to $11.5 \%$ which is acceptable for effective flour storage. Accordingly, Oladunmoye et al. [25] expressed that durum wheat semolina protein content had $12.3 \%, 0.8 \%$ ash content, carbohydrate $70.9 \%$, fat content $4 \%$ and energy 372.4 kcal. Nutrient profile as comparable to control was observed in composite flour formulae of protein, fat and ash content were increased by increasing the concentration of millet and pulse flour blends.

Correlation analysis revealed that the nutrients content of composite flour formulae 1, formulae 2 and formulae 3 showed positive linear relationship (perfect uphill) with control. Here it was presented on Fig. 2. 

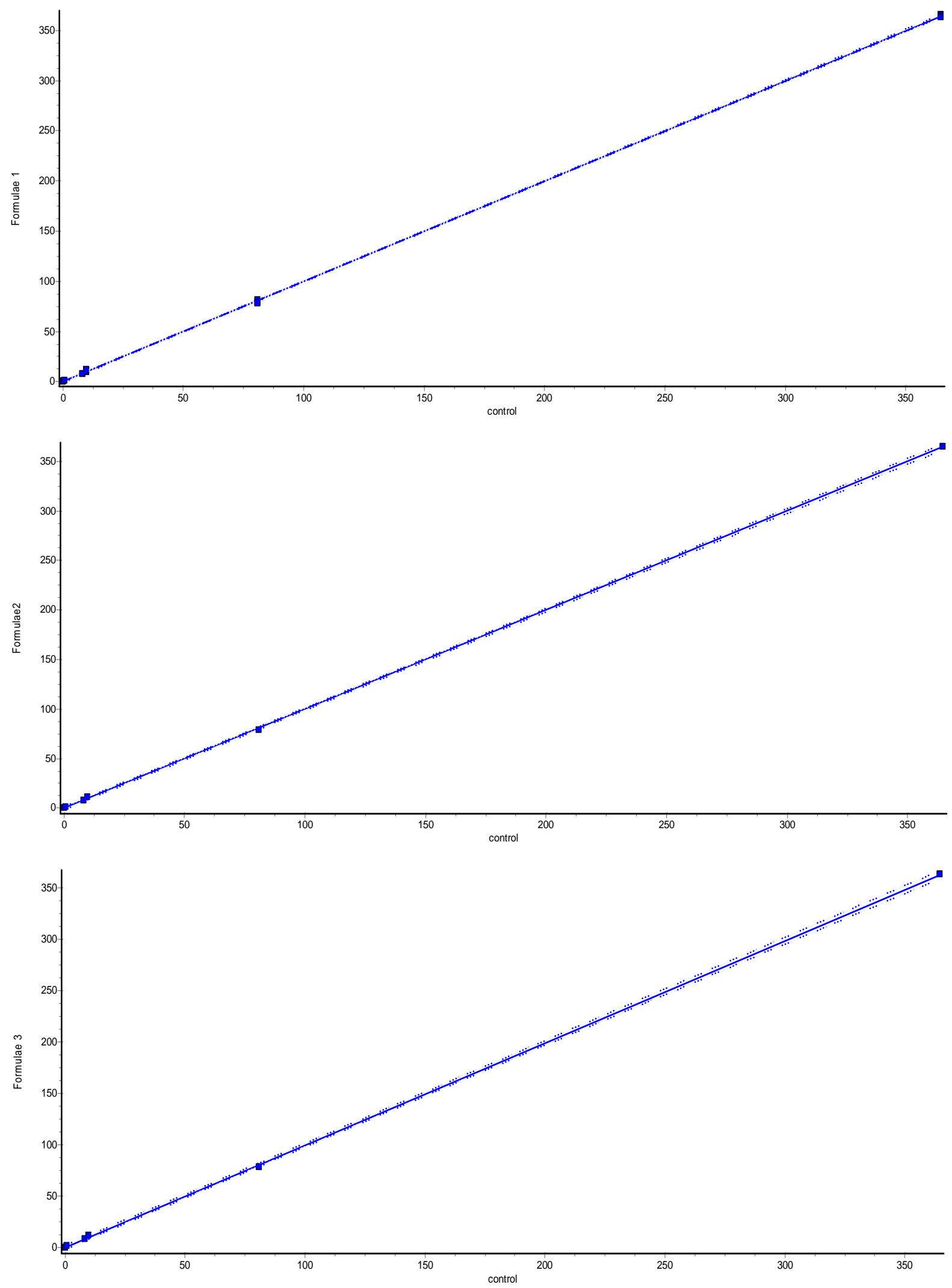

Fig. 2 Coefficient correlation of composite flour with control. 


\subsection{The Mineral Content of Flour Samples}

The mineral content of flour samples were tabulated in Table 3 and Fig. 3. The calcium content of composite mixture was $2.13,1.87$ and $2.06 \mathrm{mg}$ for formulae 1, formulae 2 and formulae 3 , respectively and control had $2.05 \mathrm{mg}$. The result showed that calcium content of composite flour was higher than control except formulae 2. While manganese contains 0.36, 0.32 and $0.31 \mathrm{mg}$ for formulae 1 , formulae 2 and formulae 3, respectively and control had $0.45 \mathrm{mg}$, from the result it could be observed that manganese content of control had higher than composite flour. Further iron content of control had $0.54 \mathrm{mg}$, formulae 1 had $0.63 \mathrm{mg}$, formulae 2 had $0.7 \mathrm{mg}$ and formulae 3 had $0.82 \mathrm{mg}$, which was higher than other flour samples. Though copper content of control had 0.06 $\mathrm{mg}$ and composite mixture of formulae 1 had $0.98 \mathrm{mg}$ and formulae 2 and 3 had $1.15 \mathrm{mg}$. At the same time zinc content of control had $0.28 \mathrm{mg}$, and composite mixture of formulae 1 had $0.34 \mathrm{mg}$, formulae 2 had $0.42 \mathrm{mg}$ and formulae $3 \mathrm{had} 0.5 \mathrm{mg}$. The result revealed that iron, copper, zinc content of composite flour formulae increased than control flour due to increased level of composite flour mixture formulae substitution with wheat flour. These results revealed that composite flour may provide sufficient amounts of minerals to meet the human mineral requirement (recommended dietary allowance (RDA)). For this reason, ratios of the mineral constituents are important for good nutrition.

\subsection{Crude Fiber Content of Flour Samples}

The crude fiber content of control had $7.88 \mathrm{~g}$, composite mixture of formulae 1 fiber content had $9.89 \mathrm{~g}$, formulae $2 \mathrm{had} 11.43 \mathrm{~g}$, and formulae $3 \mathrm{had}$ 14.06 g. From the Table 4 and Fig. 4, it can be observed that composite mixture formulae of fiber content was higher than control because composite flour has a mixture of millets, legumes and plantain so

Table 3 Minerals content of composite flour formulae.

\begin{tabular}{lllll}
\hline Nutrients content/100 & \multirow{2}{*}{ g of sample } & \multicolumn{3}{c}{ Durum wheat flour substituted with composite flour } \\
\cline { 3 - 5 } Calcium (mg) & $2.05 \pm 0.2$ & $2.13 \pm 0.03$ & Formulae 2 (30\%) & Formulae 3 (45\%) \\
Manganese (mg) & $0.45 \pm 0.01$ & $0.36 \pm 0.02$ & $1.87 \pm 0.07$ & $2.06 \pm 0.07$ \\
Iron (mg) & $0.54 \pm 0.01$ & $0.63 \pm 0.03$ & $0.32 \pm 0.02$ & $0.31 \pm 0.05$ \\
Copper (mg) & $0.06 \pm 0.03$ & $0.98 \pm 0.01$ & $0.7 \pm 0.03$ & $0.82 \pm 0.02$ \\
Zinc (mg) & $0.28 \pm 0.01$ & $0.34 \pm 0.01$ & $1.15 \pm 0.04$ & $1.15 \pm 0.04$ \\
\hline
\end{tabular}

Mean \pm standard deviation were reported; control denotes $0 \%$ composite flour substitution.

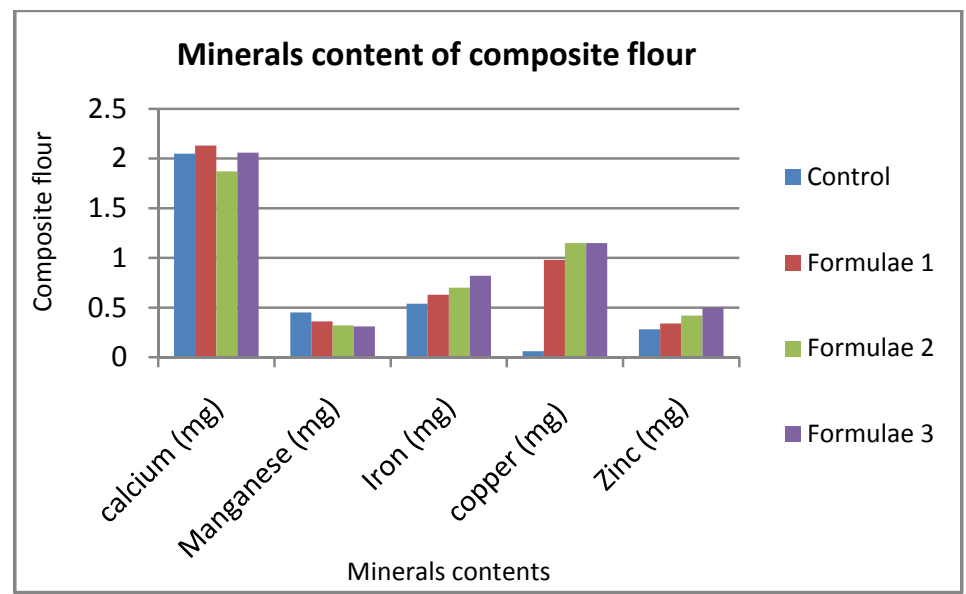

Fig. 3 Minerals content of composite flour formulae. 
Table 4 Fibre content of composite flour formulae.

\begin{tabular}{ll}
\hline Durum wheat semolina substitution with composite flour & Crude fibre $(\mathrm{g})$ \\
\hline Control & $7.88 \pm 0.4$ \\
Formulae 1 & $9.89 \pm 0.07$ \\
Formulae 2 & $11.43 \pm 0.1$ \\
Formulae 3 & $14.06 \pm 0.3$ \\
\hline
\end{tabular}

Mean \pm standard deviation were reported; control denotes $0 \%$ composite flour substitution.

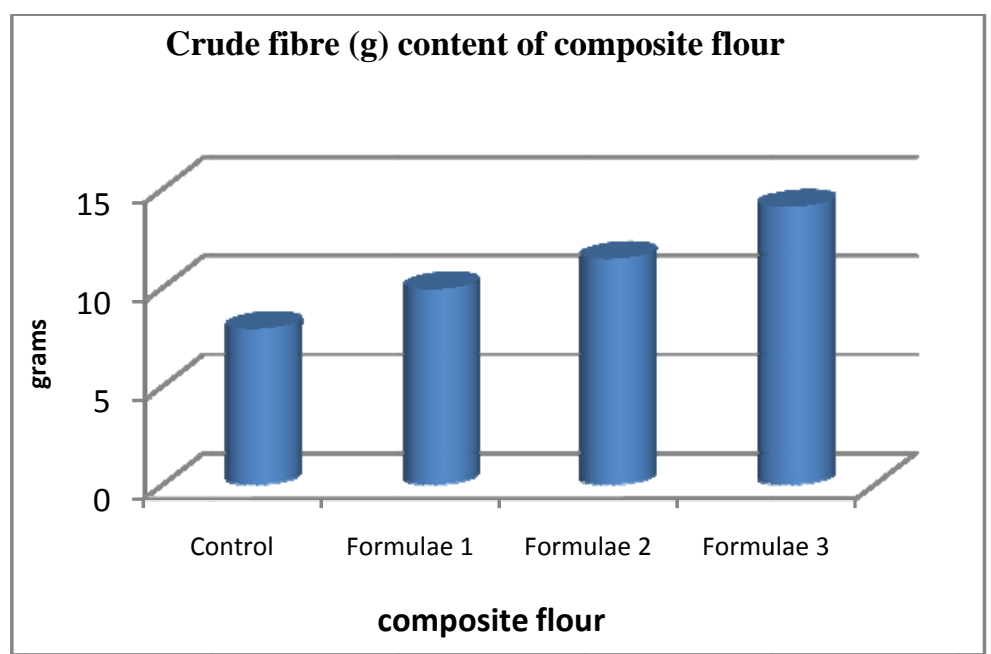

Fig. 4 Fibre content of composite flour formulae

it was more nutrient content. Further among the composite mixture formulae 3 had the higher fiber content than other samples due to the increased substitution level of composite mixture to wheat flour.

\subsection{Sensory Characteristics of Pasta Samples}

Sensory evaluation was carried out as per nine point hedonic scale (Table 5 and Fig. 5). The values are the means of 10 readings. Among the composite mixture of pasta, formulae 1 (8.81) had the highest overall acceptability, followed by formulae 2 (8.76) and formulae 3 (8.5). All these three composite mixtures of pasta were acceptability score relative to control of pasta score.

\subsection{Storage Studies of Pasta Samples}

One of the principal methods of predicting the shelf life of pasta products is to monitor the level of moisture content, ash content and sensory attributes of overall acceptability of products during food storage were presented in Table 6 and Fig. 6. The result showed that at 0 day, the moisture content of control had $7.13 \%$ after $120 \mathrm{~d}$, which was increased slightly by $7.33 \%$, followed by composite mixture of formulae 1 moisture content increase from $6.11 \%$ to $9.66 \%$, formulae 2 moisture content increase from $5.65 \%$ to $8.33 \%$ and formulae 3 moisture content increase from $4.81 \%$ to $9.16 \%$. The result found that moisture content was high at $120 \mathrm{~d}$ as compared with $0 \mathrm{~d}$. As same as the ash content of control had $0.73 \%$ at initially, it was decreased as $0.59 \%$ after $120 \mathrm{~d}$, whereas composite mixture of formulae 1 had $1.04 \%$ at initially, it was decreased as $0.84 \%$ after $120 \mathrm{~d}$, followed by formulae 2 had $1.27 \%$ at initially, it was decreased as $1.07 \%$ after $120 \mathrm{~d}$, and formulae $3 \mathrm{had}$ $1.38 \%$ at initially, it was decreased as $1.12 \%$ after 120 d. From the result observed that during storage time the composite mixture of formulae 3 pasta had the moisture content was increased rapidly and ash content was decreased rapidly at $120 \mathrm{~d}$. The pasta products shelf life studies of moisture content, ash content and overall acceptability of pasta products were 
Table 5 Sensory evaluation (nine-point scale) of pasta developed using composite flour formulae.

\begin{tabular}{lllll}
\hline \multirow{2}{*}{ Sensory attributes } & \multirow{2}{*}{ Control } & \multicolumn{3}{c}{ Durum wheat flour substituted with composite flour } \\
\cline { 3 - 5 } & & Formulae 1 (15\%) & Formulae 2 (30\%) & Formulae 3 (45\%) \\
\hline Colour \& appearance & 9 & 8 & 7.5 & 7.5 \\
Texture & 8.5 & 7.72 & 7.2 & 7.2 \\
Flavour & 8 & 7.4 & 7 & 7.2 \\
Taste & 9 & 8.86 & 8.13 & 7.86 \\
Overall acceptability & 9 & 8.81 & 8.76 & 8.5 \\
\hline
\end{tabular}

Mean scores (nine-point scale) of sensory attributes for pasta.

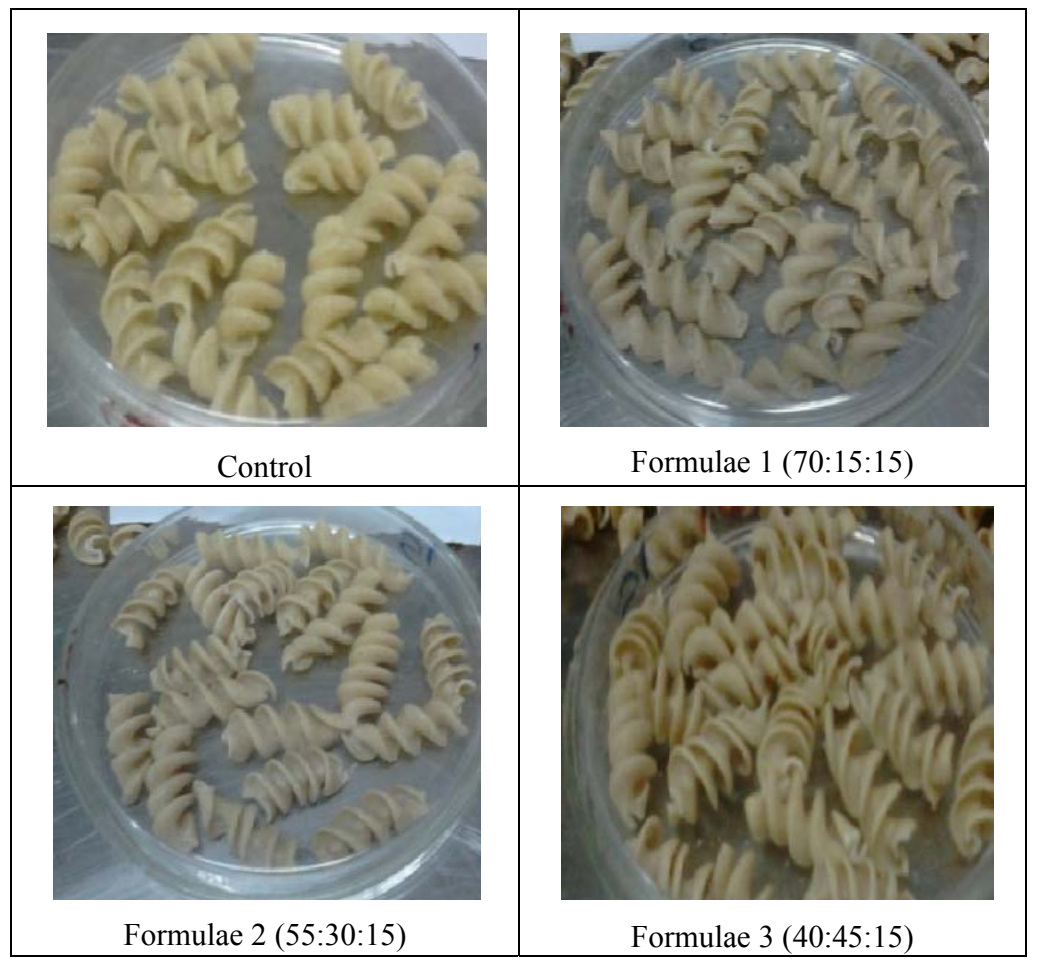

Fig. 5 Pasta products made from composite formulae.

Table 6 Effect of on storage studies of pasta developed using composite flour.

\begin{tabular}{lllllll}
\hline \multirow{2}{*}{ Composite flour } & \multicolumn{2}{l}{ Moisture content of uncooked pasta } & \multicolumn{2}{l}{ Ash content of uncooked pasta } & \multicolumn{2}{l}{ Over all acceptability of cooked pasta } \\
\cline { 2 - 6 } & $0 \mathrm{~d}$ & $120 \mathrm{~d}$ & $0 \mathrm{~d}$ & $120 \mathrm{~d}$ & $0 \mathrm{~d}$ & $120 \mathrm{~d}$ \\
\hline Control & $7.1 \pm 0.08$ & $7.3 \pm 0.2$ & $0.7 \pm 0.01$ & $0.5 \pm 0$ & $7.4 \pm 0.08$ & $6.7 \pm 0.03$ \\
Formulae 1 (15\%) & $6.1 \pm 0.13$ & $9.6 \pm 0.2$ & $1 \pm 0.01$ & $0.8 \pm 0.06$ & $7.4 \pm 0.05$ & $7.1 \pm 0.01$ \\
Formulae 2 (30\%) & $5.6 \pm 0.05$ & $8.3 \pm 0.2$ & $1.2 \pm 0.05$ & $1 \pm 0.01$ & $6.8 \pm 0.04$ & $6.2 \pm 0.05$ \\
Formulae 3 (45\%) & $4.8 \pm 0.03$ & $9.1 \pm 0.2$ & $1.3 \pm 0.04$ & $1.1 \pm 0.09$ & $6.5 \pm 0.02$ & $6 \pm 0.02$ \\
\hline
\end{tabular}

Mean \pm standard deviation were reported; control denotes $0 \%$ composite flour substitution.

displayed in Fig. 5. The pasta products were evaluated for sensory qualities for colour, flavour, texture, taste, overall acceptability by panel members at room temperature. Each member independently examined the pasta products and assigned the score on hedonic scale for its acceptability. A score of nine meant very good and a score of one indicated poor quality. After $120 \mathrm{~d}$, all the parameters of the sensory evaluation indicated that there is decrease in the scores of pasta products prepared from composite mixture of 


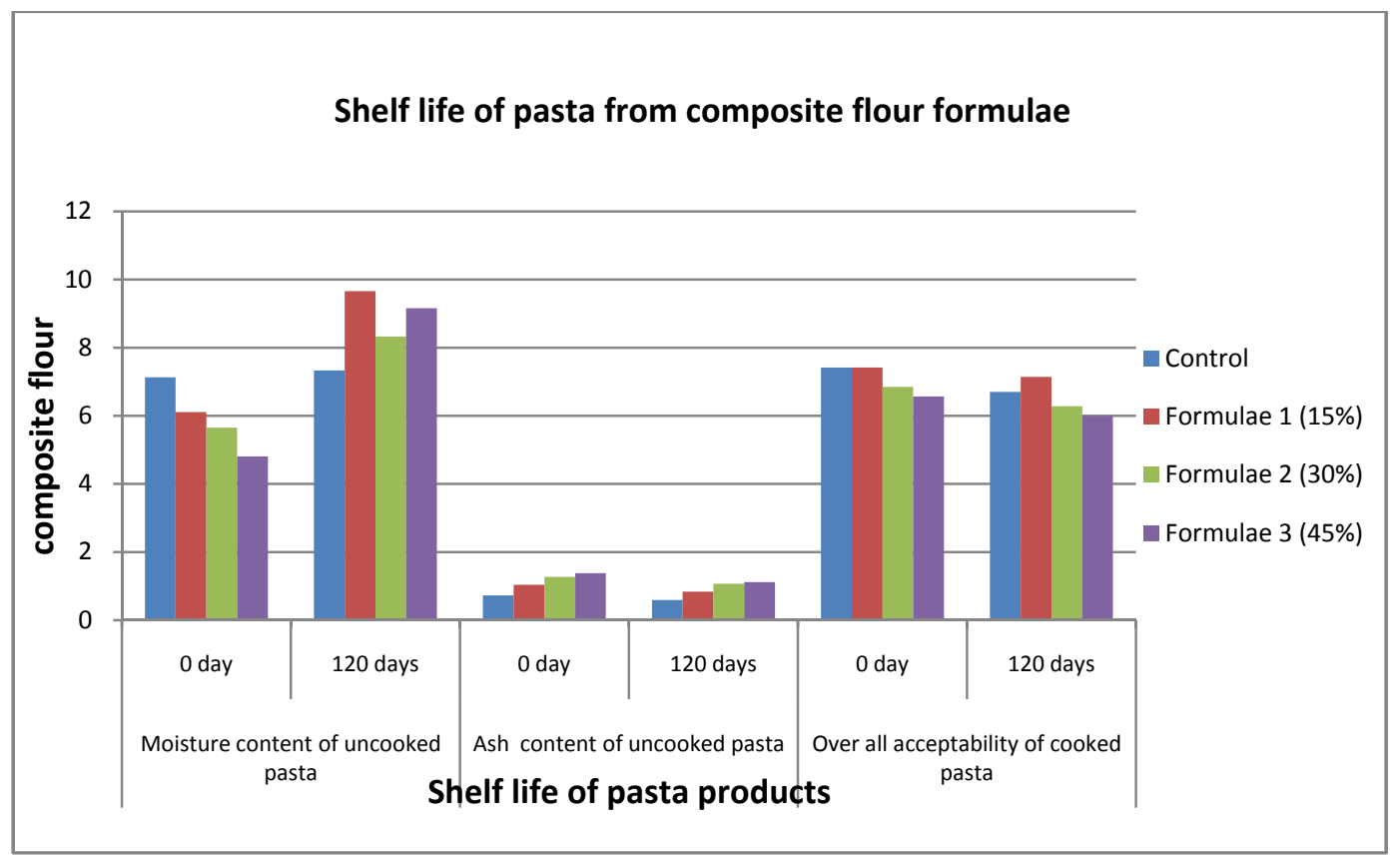

Fig. 6 Storage studies of composite flour formulae.

formulas and control. It is also interesting to note that the drop in the scores of sensory evaluation was higher in composite mixture of formulae 1 (7.1) had overall acceptability compared to the other samples. Deteriorative changes in read to eat extruded snack during storage and exposure to atmosphere are loss of flavour, development of rancidity and softening of texture [12, 26]. Coulibaly et al. [19] reported that the stability of the food during storage is important; some deterioration in cereal-legume blends during storage is mostly caused by fat oxidation due to deterioration in taste, flavor, odor, color, texture and appearance, and a decrease in the nutritional value of the foods.

\section{Conclusions}

The most serious nutritional problem of the world is protein calorie malnutrition (PCM), especially in the developing countries. The lower income group of the population is particularly vulnerable, because of its low purchasing power of this group. Attention, therefore, must be focused on the cheap, but nutritious plant protein sources, such as cereals, pulses and vegetable. It is advisable to enhance the protein content of easily available and accessible plant protein sources (especially legumes) to improve the nutritional status of the low-income groups of the population. Among the cereal grains, millet has more healthy benefits and better nutritious than other major cereals such as rice and wheat. Hence millet is called as miracle grain. Although addition with $15 \%$ of plantain flour incorporated to blend of millets, pulses flour to obtain nutritious composite flour which is more fiber and resistant starch content. The present work revealed that pasta could be made using multi grain and plantain flour for the nutritional improvements to get high quality food products. Hence formulated the composite mixture of formulae such as durum semolina, millet, pulse blend flour and plantain flours in different ratios such as 70:15:15, 55:30:15 and 40:45:15 showed higher nutritive value especially protein, crude fiber, carbohydrate, ash and mineral contents. All the three composite mixtures of formulae could be used to produce pasta products of good quality. Among the composite mixtures, formulae1 had high score in overall acceptability. During storage period, composite mixture of formulae nutrients content and also sensory parameters were slightly decreased. Product shelf life is important for 
quality and economic reasons. During storage period of food, the stability of the food has been deteriorated due to oxidation, hydrolysis and thermal decomposition by chemical reactions occur in food which are affect the sensory and nutritional quality of food. Although, in post-harvest technology, the value addition technology has given the opportunities to prepare and enhanced the process products which are accepted by both urban and rural consumers. Hence the multigrain food products provide the good health, appealing color, good taste and other beneficial effect like extended shelf life. So these foods are also economically feasible for all grades of population.

\section{Acknowledgments}

The authors are thankful to University Grants Commission (UGC) for providing financial support to complete this project as UGC-JRF. Authors would like to express their gratitude to the director, Central Food Technological Research Institute (CFTRI), Mysore for permitting them to use their infrastructure facilities available in the Department of Flour Milling, Bakery and Confectionery Technology.

\section{References}

[1] Bashir, K., Aeri, V., and Masoodi, L. 2012. "Physio-Chemical and Sensory Characteristics of Pasta Fortified with Chickpea Flour and Defatted Soy Flour." IOSR Journal of Environmental Science, Toxicology and Food Technology (IOSR-JESTFT) 1 (5): 34-9.

[2] Singh, P., and Raghuvanshi, R. S. 2012. "Finger Millet for Food and Nutritional Security." African Journal of Food Science 6 (4): 77-84.

[3] Del Nobile, M. A., Baiano, A., Conte, A., and Mocci, G. 2005. "Influence of Protein Content on Spaghetti Cooking Quality." Journal of Cereal Science 41: 347-56.

[4] Singh, P., Singh, G., Srivastava, S., and Agarwal, P. 2005. "Physico-Chemical Characteristics of Wheat Flour and Millet Flour Blends." Journal of Food Science and Technology 42 (4): 340-3.

[5] Changmei, S., and Dorothy, J. 2014. "Millet the Frugal Grain.” International Journal of Scientific Research and Reviews (IJSRR) 3 (4): 75-90.

[6] Truswell, A. S. 2002. "Cereal Grain and Coronary Heart Disease." European Journal of Clinical Nutrition 56 (1): $1-4$.
[7] Gupta, N., Srivastava, A. K., and Pandey, V. N. 2012. "Biodiversity and Nutraceutical Quality of Some Indian Millets." Proceedings of the National Academy of Sciences, India Section B: Biological Sciences 82 (2): 265-73.

[8] Platel, K., Eipeson, S. W., and Srinivasan, R. 2010. "Bio Accessible Mineral Content of Malted Finger Millet (Eleusine coracana), Wheat (Triticum aestivum), and Barley (Hordeum vulgare)." Agricultural and Food Chemistry 58: 8100-3.

[9] Mal, B., Padulosi, S., and Ravi, S. B. eds. 2010. Minor Millets in South Asia: Learnings from IFAD-NUS Project in India and Nepal. Maccarese, Rome, Italy: Bioversity International and Chennai, India, Swaminathan, M. S. Research Foundation, 1283-5.

[10] Borsuk, Y., Arntfield, S., Lukow, O., Swallowc, K., and Malcolmsond, L. 2012. "Incorporation of Pulse Flours of Different Particle Size in Relation to Pita Bread Quality." J. Sci. Food Agric. 92: 2055-61. doi: 10.1002/jsfa.5581.

[11] Amjad, I., Khalil, I. A., and Shah, H. 2003. "Nutritional Yield and Amino Acid Profile of Rice Protein as Influenced by Nitrogen Fertilizer." Sarhad Journal of Agriculture 19: 127-34.

[12] Sharma, S., Bajwa, U. H., and Nagi, H. P. S. 1999. "Rheological and Baking Properties of Cowpea and Wheat Flour Blends." Journal Science Food Agriculture 79: 657-62.

[13] Hefnawy, T. M. H., El-Shourbagy, G. A., and Ramadan, M. F. 2012. "Impact of Adding Chickpea (Cicer arietinum L.) Flour to Wheat Flour on the Rheological Properties of Toast Bread.” International Food Research Journal 19 (2): 521-5.

[14] Wang, N., Hatcher, D. W., Tyler, R. T., Toews, R., and Gawalko, E. J. 2010. "Effect of Cooking on the Composition of Beans (Phaseolus vulgaris L.) and Chickpeas (Cicer arietinum L.)." Food Research International 43: 589-94.

[15] Duranti, M. 2006. "Grain Legume Proteins and Nutraceutical Properties.” Fitoterapia 77 (2): 67-82.

[16] Amankwah, E. A., Ayin, I., Dzisi, K., and Barimah, J. 2011. "Nutritional Content and Functional Properties of French Horn, False Horn and FHIA-21." American Journal of Food Technology 6 (4): 322-8.

[17] Fasolin, L. H. 2007. "Biscoitos Produzidos Com Farinhade Banana: Avaliações Química, Física e Sensorial." Ciência e Tecnologia de Alimentos, Campinas 7 (3): 524-9.

[18] AACC. 2000. Approved Methods of the American Association of Cereal Chemists. 10th edition. St. Paul: American Association of Cereal Chemists, Inc.

[19] Coulibaly, A., Kouakou, B., and Chen, J. 2012. "Extruded Adult Breakfast Based on Millet and Soybean: 
Nutritional and Functional Qualities, Source of Low Glycemic Food." J. Nutr. Food Sci. 2 (7): 151. doi: 10.4172/2155-9600.1000151.

[20] Mullan, W. M. A. 2006. "Labelling-Determination of the Energy Content of Food." Accessed July 25, 2018. https://www.dairyscience.info/index.php/packaging/119-1 abelling-determination-of-the-energy-content-of-food.ht $\mathrm{ml}$.

[21] Yadilal, G., Manisha, M., Pavani, E., Navya, M., Alekhya, C., Chandini, H., and Madhu, C. 2017. "Estimation of Crude Fibre Content in Spices and Fruits." Indo American Journal of Pharmaceutical Sciences 4 (10): 3864-8.

[22] Mahajan, S., and Chauhan, B. M. 1988. "A Research Note Effect of Natural Fermentation on the Extractability of Minerals from Pearl Millet Flour." Journal of Food Science 53:1576-7.

[23] Krishnan, J., Menon, R., Padmaja, G., Sajeev, M. S., and
Moorthy, S. N. 2012. "Evaluation of Nutritional and Physico-mechanical Characteristics of Dietary Fiber-Enriched Sweet Potato Pasta." European Food Research and Technology 234: 467-76.

[24] Hayma, J. 2003. The Storage of Tropical Agricultural Products. Wageningen, Netherlands: Agromisa Foundation, 84.

[25] Oladunmoye, O. O., Aworh, O. C., Maziya-Dixon, B., Erukainure, O. L., and Elemo, G. N. 2014. "Chemical and Functional Properties of Cassava Starch, Durum Wheat Semolina Flour, and Their Blends." Food Science \& Nutrition 2 (2): 132-8.

[26] Gulla, S., and Waghray, K. 2012. "Blending of Oils: A Case Study on Storage Stability and Sensory Characteristics of Ready to Eat Extruded Snack." Journal of Nutrition, Dietetics and Food Science 2 (1): 1-12. 